This item was submitted to Loughborough's Research Repository by the author.

Items in Figshare are protected by copyright, with all rights reserved, unless otherwise indicated.

\title{
Competition between crystallization and coalescence during the film formation of poly(chloroprene) latex and effects on mechanical properties
}

\section{PLEASE CITE THE PUBLISHED VERSION}

https://doi.org/10.1021/acs.iecr.9b02279

\section{PUBLISHER}

(C) American Chemical Society (ACS)

\section{VERSION}

AM (Accepted Manuscript)

\section{PUBLISHER STATEMENT}

This document is the Accepted Manuscript version of a Published Work that appeared in final form in Industrial \& Engineering Chemistry Research, copyright $\odot$ American Chemical Society after peer review and technical editing by the publisher. To access the final edited and published work see https://pubs.acs.org/doi/10.1021/acs.iecr.9b02279.

\section{LICENCE}

CC BY-NC-ND 4.0

\section{REPOSITORY RECORD}

Richardson, Philip G., Ignacio Martin-Fabiani, Patrick Shaw, Eman Alsaffar, Emilie Velasquez, Paul Gardner, Peter Shaw, James M. Adams, and Joseph L. Keddie. 2019. "Competition Between Crystallization and Coalescence During the Film Formation of Poly(chloroprene) Latex and Effects on Mechanical Properties". figshare. https://hdl.handle.net/2134/38329. 


\section{Competition between Crystallization and}

\section{Coalescence during the Film Formation of}

\section{Poly(Chloroprene) Latex and Effects on Mechanical Properties}

Philip Richardson, ${ }^{1 \dagger}$ Ignacio Martin-Fabiani, ${ }^{2}$ Patrick Shaw, ${ }^{1 \#}$ Eman Alsaffar, ${ }^{3 *}$ Emilie Velasquez, ${ }^{3}$ Paul Gardner, ${ }^{3}$ Peter Shaw, ${ }^{3}$ James M. Adams, ${ }^{1}$ Joseph L. Keddie ${ }^{1 *}$

${ }^{1}$ Department of Physics, University of Surrey, Guildford, Surrey GU2 7XH, United Kingdom

${ }^{2}$ Department of Materials, Loughborough University, Loughborough LE11 3TU, Leicestershire, United Kingdom

${ }^{3}$ Synthomer (UK) Limited, Central Road, Harlow, Essex CM20 2BH, United Kingdom 
ABSTRACT. Poly(chloroprene) is a synthetic crystallizable polymer used in several applications, including rubber gloves. The film formation of poly(chloroprene) latex offers opportunities to define structures at length scales between the molecular and macroscopic, thereby adjusting the elastomer's mechanical properties. However, the connections between processing and the resultant film properties are not fully understood. Here, we investigate the competition between the coalescence of latex particles to build cohesive strength and their crystallization to raise the elastic modulus. We demonstrate that when coalescence precedes crystallization, the elastomer has greater extensibility and a higher tensile strength compared to when crystallization occurs during coalescence. The mechanical properties of poly(chloroprene) were tuned by blending two colloids with differing gel contents and crystallizabilities. Heating above poly(chloroprene)'s melting temperature allows increased particle interdiffusion and builds cohesion, prior to recrystallization. We provide evidence from in situ wide-angle X-ray scattering for the strain-induced crystallization of as-cast films from particle blends.

\section{Introduction}

Colloidal polymer particles in water, known as latex, are used in the manufacture of a range of industrial products, including gloves, condoms, adhesives, coatings, and carpet backing. ${ }^{1}$ A natural source of latex, containing cis-isoprene, is obtained from Hevea Brasiliensis trees. ${ }^{2}$ However, proteins that act as emulsifiers in this natural latex can lead to potentially fatal allergic reactions in humans, with a particular risk of contact dermatitis for wearers of latex gloves.

Unfortunately, one in ten people reportedly exhibits sensitization to the protein, leading to skin irritation. ${ }^{3}$ Consequently, to prevent these adverse reactions for wearers of gloves, a range of 
alternative synthetic latex has been developed as replacements for natural rubber. Example compositions include poly(isoprene), nitrile-butadiene rubber, and poly(chloroprene). ${ }^{4}$

A variety of polymers used in the glove industry can undergo crystallization during processing. The crystallization behavior and resulting mechanical properties of natural latex rubber and poly(isoprene), both non-strained ${ }^{5}$ and strained, ${ }^{6,7}$ have been studied extensively over the past half century. It has been known for decades that poly(chloroprene) can crystallize, ${ }^{8}$ and some information on its crystallization behavior during mechanical deformation in the bulk form has been reported. ${ }^{9}$ The particular isomer of poly(chloroprene) determines whether crystals can form in non-strained films. Chains with a high fraction of the 1,4-trans isomer are able to crystallize, whereas the presence of cis isomers hinders crystallization. ${ }^{10}$ The crystallization of poly(chloroprene) latex films has been investigated as a function of time using the ultrasonic shear wave reflection technique. ${ }^{10}$ Nevertheless, a thorough understanding of how the latex processing parameters affect crystallization is needed, and hence it is the focus of our current research.

Under sufficiently high strains, the alignment of linear chain molecules in an elastomer can result in their partial crystallization via strain-induced crystallization (SIC). Following the first reports in natural rubber in $1925,{ }^{11} \mathrm{SIC}$ has since been thoroughly examined in both natural rubber ${ }^{7,12,13}$ and synthetic poly(isoprene), ${ }^{14,15}$ with extensive use of in-situ X-ray scattering. It is predominantly observed at strains greater than $300 \%$. SIC results in an increased elastic modulus during a high extension. Lamellar crystal structures are developed in natural rubber perpendicular to the direction of strain, leading to the formation of a 'shish-kebab' structure. ${ }^{16}$ Poly(chloroprene) likewise undergoes SIC, but there are only a few reports in the literature. The published research on SIC in poly(chloroprene) has focused on bulk vulcanized (i.e. cross-linked) samples. ${ }^{9,17}$ In an initial non-strained elastomer, the vulcanization (or cross-linking) inhibits crystallization in 
polychloroprene, ${ }^{9,10}$ presumably because it reduces whole chain mobility. Strain-hardening arising from SIC in polychloroprene has been recently reported, and it was attributed to the presence of interacting crystal networks. ${ }^{17}$ In the present work, we investigate colloidal poly(chloroprene) with two different gel contents in relation to their resulting crystallinity and mechanical properties.

Film formation is required to transform the poly(chloroprene) latex particles into an elastomer. Latex film formation occurs over three key processes, ${ }^{18}$ as are depicted in Figure 1. Firstly, particles pack together into an array. For typical colloidal coatings, evaporation of the water phase leads to particle packing. However, in the coagulation-dip process, which is used in glove manufacturing, a salt is used to destabilize the latex and cause rapid coagulation at the interface with a mold, called a former. ${ }^{19}$ Secondly, particle deformation ${ }^{20}$ occurs under the forces of capillarity as water evaporates from the film and to achieve the reduction of interfacial free energy. Particles with a low viscosity undergo deformation in the presence of water. ${ }^{21}$ Finally, the particle/particle boundaries disappear as the constituent polymer chains diffuse by reptation across the interfaces. ${ }^{22}$

The cohesive strength of a latex film is built up in this final step. Diffusion leads to a higher tensile strength because of the greater cohesion between particles as polymer chains become entangled with each other across the interfaces. ${ }^{23}$ Elevating the temperature of the polymer chains increases their mobility and their rate of interdiffusion. ${ }^{24}$

When considering a polymer that undergoes crystallization during film formation, we propose a modification of the conventional model of film formation. We expect that the first two processes (particle packing and deformation) will occur as normal for crystallizable polymer particles. Thereafter, there will be a competition between the crystallization of chains within particles (and clusters) and the coalescence of those particles. The relative rates of each process will determine 
which one first reaches completion. We propose that if the rate of crystallization is much faster than the rate of coalescence, then crystals could form at a particle's surface and prevent chain extension and entanglements across the interface with its neighboring particles. Figure 1 illustrates this crystallization-led scenario. A film with distinct boundaries remaining between crystalline domains is expected to be weaker under high strain.

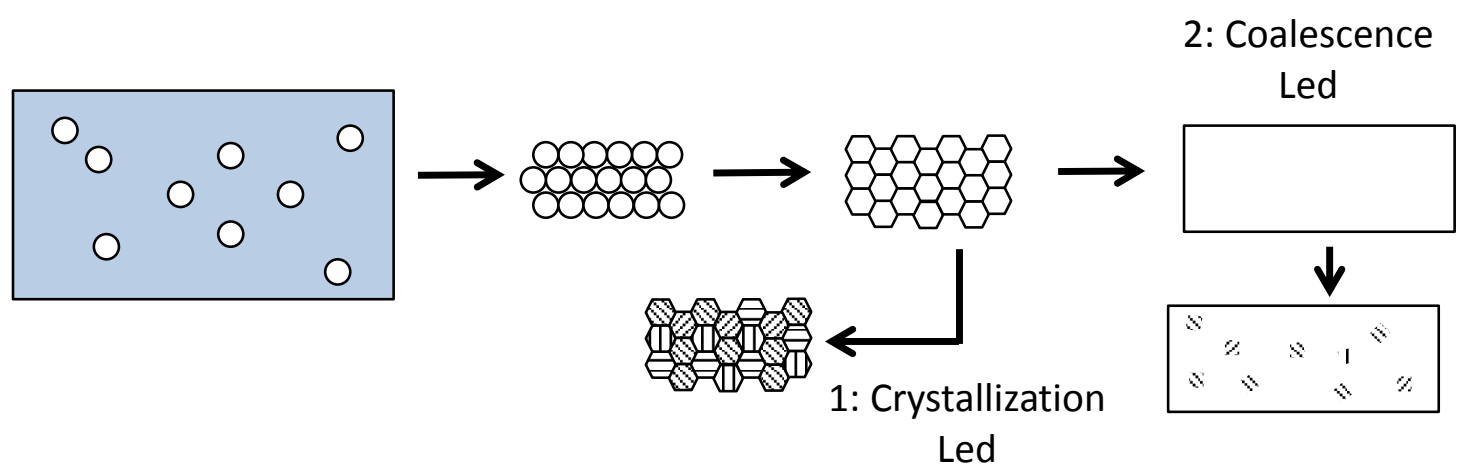

Figure 1. Visual representations of the proposed scenarios of latex film formation which occur when the rate of crystallization is much faster than the rate of coalescence (Scenario 1), or when coalescence is much faster than the crystallization (Scenario 2). Here it is assumed for simplicity that the crystal size is the same as the particle size.

If the reverse is true, then the film will become fully coalesced prior to the onset of crystallization. Boundaries between particles will be removed prior to crystallization. This coalescence-led process is illustrated as Scenario 2 in Figure 1. We expect that the resulting film will have greater cohesion between the particles, leading to a film that can withstand higher strains before fracture. As tests of our hypotheses, in this research we compare the mechanical properties of poly(chloroprene) films processed to achieve either coalescence-led or crystallization-led structures. We also investigate the effect of heating films formed under a crystallization-led scenario to allow coalescence to occur prior to their re-crystallization at room temperature. Our model of competing processes has been inspired by previous research by the groups of El-Aasser ${ }^{25}$ 
and deGennes ${ }^{26,27}$ in which the competing effects of chain cross-linking and particle coalescence were considered.

For film formation from crystallizable latex particles, the characteristic time for crystallization, $\tau_{\text {cryst }}$ can be compared to the characteristic time for coalescence, $\tau_{\text {coal }}$. An estimate of $\tau_{\text {cryst }}$ can be obtained from the size of a latex particle divided by the crystal growth velocity. We are not aware of any values for the crystal growth velocity of poly(chloroprene) reported in the literature. However, Fischer and Henderson ${ }^{28}$ reported a velocity of $500 \mathrm{~nm} / \mathrm{min}$. for poly(isoprene). Although there will be an effect from the pendant $\mathrm{Cl}$ moieties in poly(chloroprene), this number should be an adequate estimate. For particles on the order of $100 \mathrm{~nm}$ in diameter, $\tau_{\text {cryst }}$ is estimated to be on the order of $10 \mathrm{~s}$.

$\tau_{\text {coal }}$ represents the time for the chains to interdiffuse far enough for there to be no distinct particle boundaries. It can be estimated from the reptation time, $\tau_{\text {rep}}$, for the entire chain to diffuse out of its initial tube of entanglements. The model of reptation developed by de Gennes ${ }^{29}$ can be used to calculate $\tau_{\text {rep }}$ as

$$
\tau_{\text {rep }}=\frac{\zeta b^{2} N^{3}}{k_{B} T N_{e}}
$$

where $\zeta$ is the friction coefficient of monomer units, $b$ is the Kuhn length, $N$ is the total number of monomer units in a chain, $N_{e}$ is the number of units between chain entanglements, $k_{B}$ is the Boltzmann constant, and $T$ is the absolute temperature. Values of the relevant parameters for poly(chloroprene) are lacking in the literature. Using values for poly(1-4 isoprene) of $b=1 \mathrm{~nm}, N_{\mathrm{e}}$ $=50($ ref. 15$)$ and $\zeta$ to be $3 \times 10^{-10} \mathrm{kgs}^{-1}$ (ref. 30), we estimate $\tau_{\text {rep }}$ to be on the order of $2 \mathrm{~s}$ at room temperature for poly(chloroprene) for a molecular weight of $100 \mathrm{~kg} / \mathrm{mol}(N=1130)$. It is likely that $\zeta$, and hence $\tau_{\text {rep}}$, will be greater for poly(chloroprene) because of its pendant $\mathrm{Cl}$ moieties. 
From this very rough estimate, the most that we can safely conclude is that $\tau_{\text {coal }}$ and $\tau_{\text {cryst }}$ will be comparable for poly(chloroprene). We expect that changes in the temperature and the polymer molecular weight will tilt the balance so that one is dominant over the other.

Previous work by the group of El-Aasser ${ }^{31}$ demonstrated that the latex particle nanostructure, as well as interfacial bonding, can be designed to modify the mechanical properties of elastomers. Blending of different types of colloidal polymer particles ${ }^{32,33}$ (including rubbers ${ }^{34}$ ) is often used to 'tune' the mechanical properties of the resulting composite. Previous studies of poly(chloroprene)

have focused on blending with a variety of other materials, such as natural rubber, ${ }^{35}$ silica, ${ }^{36}$ and poly(styrene-acrylate). ${ }^{37}$ In this work, we investigate the effects of blending, over a range of proportions, for two poly(chloroprene) latexes with differing gel contents (and hence different abilities to crystallize). The effects of this particle blending on the crystallization and mechanical properties of the elastomer will be reported in relation to the competition between crystallization and coalescence. We also investigate whether strain-induced crystallization occurs in blends of these two latexes, in order to generate another means to adjust the mechanical properties of the resultant material.

\section{Materials and Methods}

\section{Materials}

Two samples of poly(chloroprene) latex, sold under the commercial name of Lipren ${ }^{\circledR}$, were supplied by Synthomer (UK) Ltd. and used as-received. The latex particles are comprised of crosslinked polymers (discussed later); therefore, no accelerators or peroxides are included in the formulation. Table 1 shows an overview of some of the key physical properties of each material. The particle size was measured using dynamic light scattering (Malvern Zetasizer Nano Series, 
Malvern, UK). The gel content was determined after extracting the sol component with hot toluene (using a $125 \mathrm{~mL}$ Soxhlet extraction apparatus fitted with a $25 \mathrm{~mm} \times 85 \mathrm{~mm}$ porous glass thimble (Supelco)) over a total period of $24 \mathrm{~h}$, from films $(0.7 \mathrm{~mm}$ thick) that had been cast in glass dishes and dried in air at room temperature for seven days. The gel content was calculated from the ratio of the film mass after the extraction of the sol component to the mass before the extraction. The values of the gel fraction are presented in Table 1. Hereafter, we refer to the two poly(chloroprene) latexes according to their gel content as PC53 and PC94. NMR analysis of PC53 following the method of Makhiyanov ${ }^{38}$ (see Figure S1 in Supporting Information) found that $91.4 \%$ of the noncross-linked sol molecules consisted of the 1,4 trans isomer, which is the isomer that is most able to crystallize, ${ }^{11}$ along with $5.2 \%$ in the non-crystallizing 1,4 cis isomer. NMR spectroscopy was attempted on PC94, however because of the high gel content, it was not possible to obtain sufficient quantities in the chloroform solvent to acquire adequate NMR spectra.

The glass transition temperature, $T_{\mathrm{g}}$, and crystal melting temperature, $T_{\mathrm{m}}$, were measured by differential scanning calorimetry (DSC) (Q1000, TA Instruments, New Castle, USA) under a nitrogen atmosphere using a heat $/ \mathrm{cool} /$ heat cycle with a ramp rate of $10{ }^{\circ} \mathrm{C} / \mathrm{min}$. Mid-point values were obtained from the second heating scan. Table 1 shows that the $T_{\mathrm{g}}$ is the same for PC53 and PC94, and only PC53 exhibits a melting temperature to provide evidence for crystallinity. See the DSC traces in Figure S2 (Supporting Information). No melting transition endotherm was observed in the DSC trace for PC94.

In some experiments, wet colloidal dispersions of PC53 and PC94 were blended together by slow addition, stirred for $10 \mathrm{~min}$. using a magnetic stirrer, and then allowed to rest overnight. The blends were made with volume ratios of wet latex of 3:1, 1:1, and 1:3 (PC53:PC94). Prior to casting thick films, the latex blend was re-stirred for 10 minutes. 
Table 1. Summary of the Characteristics of the Two Poly(chloroprene) Latexes

\begin{tabular}{|c|c|c|}
\hline $\begin{array}{l}\text { Characteristic or } \\
\text { Property }\end{array}$ & PC53 & PC94 \\
\hline Particle Size (nm) & 125 & 174 \\
\hline Polydispersity index & 0.086 & 0.072 \\
\hline $\begin{array}{l}\text { Weight-average molecular } \\
\text { weight, } M_{\mathrm{w}}\left(\mathrm{g} \mathrm{mol}^{-1}\right)\end{array}$ & 260 & n.a.* \\
\hline Dispersity, $\varnothing$ & 13.6 & n.a. * \\
\hline Solids content (wt. \%) & 55 & 58 \\
\hline $\begin{array}{l}\text { Dispersion viscosity } \\
\text { according to ISO } 1652 \\
(\mathrm{mPa} \mathrm{s})\end{array}$ & $<160$ & 80 \\
\hline Zeta potential (mV) & -42.6 & -60.5 \\
\hline Gel content (wt. \%) & 53 & 94 \\
\hline$T_{\mathrm{g}}$ mid-point $\left({ }^{\circ} \mathrm{C}\right)$ & -42 & -42 \\
\hline$T_{\mathrm{m}}\left({ }^{\circ} \mathrm{C}\right)$ & 28 & none \\
\hline
\end{tabular}

* Could not be determined because a sufficient quantity of sol molecules could not be extracted.

\section{Methods}

Gel Permeation Chromatography (GPC). The molecular weight of the PC53 sol polymer was characterized after dissolution of a fully dry film in tetrahydrofuran. The dissolved film was passed through a $0.45 \mu \mathrm{m}$ pore-size PTFE membrane to yield a solution concentration of $10 \mathrm{mg} \mathrm{mL}^{-1}$. Gel permeation chromatography measurements were performed in THF at $40{ }^{\circ} \mathrm{C}$ using a flow rate of $1 \mathrm{~mL} \mathrm{~min}{ }^{-1}$. The separation was carried out on three columns (Agilent PLgel $(300 \mathrm{~mm} \times 7.5$ $\mathrm{mm}$ ) with a $10 \mu \mathrm{m}$ film thickness). The instrument (Agilent Infinity 1260) is equipped with a 
differential refractive index (RI) detector $(\lambda=658 \mathrm{~nm})$ and a viscometer detector. The numberaverage molar mass $\left(M_{\mathrm{n}}\right)$ and dispersity $\left(\nexists=M_{\mathrm{w}} / M_{\mathrm{n}}\right)$ were calculated with a universal calibration based on a polystyrene standard kit (InfinityLab EasiVial PS-H). The dispersity of the PC53 sol molecules is very large (Table 1). Because of the high gel content and the effects of chain entanglements in the PC94 polymer, it was not possible to extract sufficient quantities of the sol to enable characterization of its molecular weight.

Zeta Potential Measurements. The zeta potentials of the two types of particles were measured after dilution using folded capillary cells in a Zetasizer Nano ZS90 (Malvern Instruments, UK). A refractive index of 1.500 and an absorption coefficient of 0.01 was assumed in the analysis. Both types of particles have negative charges to impart colloidal stability.

Differential Scanning Calorimetry (DSC). DSC was used to investigate the re-crystallization. Samples were placed in standard aluminum pans and experiments were performed under nitrogen (Q1000, TA Instruments, New Castle, DE, USA).

Samples were initially heated from room temperature to $65^{\circ} \mathrm{C}$ and then held there for $30 \mathrm{~min}$. to ensure that all crystals had been melted. The samples were then cooled to $22{ }^{\circ} \mathrm{C}$ and held for differing periods of time to allow re-crystallization to take place. After the allotted time, the sample was ramped at $10{ }^{\circ} \mathrm{C} / \mathrm{min}$ to $65^{\circ} \mathrm{C}$ to melt the newly-formed crystals. The measured enthalpy of melting was used to estimate the fraction of crystallinity. The protocol is shown in Scheme S1 (Supporting Information).

In experiments with re-crystallization times of one or more days, the samples were placed in an oven at $65{ }^{\circ} \mathrm{C}$ for $30 \mathrm{~min}$. to melt the crystals and then held at room temperature during the recrystallization period. 
Tensile Stress/Strain Analysis. Wet latex was cast in glass Petri dishes (6 cm diameter) and dried for one week at room temperature to ensure complete drying. (In prior experiments, thermogravimetric analysis was performed on films drying over time. It was concluded that the films reached a water content of $0.6 \mathrm{wt} . \%$ after one week of drying. An additional week of drying had no significant effect on this residual water content. Hence, the subsequent sample preparation allowed one week for film drying.)

After one week, the films were removed from their Petri dishes. Rectangular strips were cut using a scalpel to have typical dimensions of $3 \mathrm{~mm} \times 20 \mathrm{~mm}$ and with a thickness of $0.5 \mathrm{~mm}$. The width and thickness of the strips were measured with digital calipers prior to testing.

Large tensile strain analysis of free-standing poly(chloroprene) films was performed on a tensile apparatus fitted with pneumatic grips (Instron 5500R - 1185). A $100 \mathrm{kN}$ load cell was used for all experiments.

Samples were clamped in the pneumatic grips, and the gauge length was measured using the read-out on the instrument prior to beginning the experiment. All samples were strained at a constant crosshead velocity of $6 \mathrm{~mm} / \mathrm{min}$. Typically, three replicate experiments were performed, which were used to calculate the mean values of the Young's modulus, strain at failure, and energy to failure (obtained from the area under the stress/strain curves). The engineering stress (calculated from the initial cross-sectional area) and engineering strain (calculated as the dimensionless ratio of the change in length divided by the initial gauge length) are presented in this paper.

Two film processing protocols were developed to simulate the two scenarios outlined in the Introduction, and the two scenarios were combined together in a third processing protocol. Figure 2 presents the temperature schedules for these processes over time (2a) and as a function of the latex solids content (expressed as the particle volume fraction) as drying proceeds ( $2 b$ ). 
Crystallization-led Process (Scenario 1): Film formation occurred at room temperature (below $\left.T_{\mathrm{m}}\right)$ over one week. Room temperature was in the range from 20 to $22{ }^{\circ} \mathrm{C}$ for all experiments.

Coalescence-led Process (Scenario 2): Latex was cast in a glass Petri dish and placed directly in a convection oven (SANYO MOV-112F) with air pre-heated to $50{ }^{\circ} \mathrm{C}$ to undergo film formation over a period of $24 \mathrm{~h}$. This temperature is above $T_{\mathrm{m}}$, so that the drying and coalescence of the film was forced to occur in the absence of crystals. The film was cooled to room temperature and aged for 24 hours to enable crystallization to occur.

Mixed Process (Scenario 1+2): The processes of scenarios 1 and 2 were combined in succession. The film was dried and film-formed at room temperature for one week to enable crystallization as in Scenario 1. It was then heated to melt the poly(chloroprene) crystals and to drive coalescence (as in Scenario 2). Specifically, the free-standing film was placed on a glass plate into the preheated oven set at a temperature of $65^{\circ} \mathrm{C}$, and held for $30 \mathrm{~min}$., before being removed and cooled to room temperature. Finally, the film was held for one day at room temperature to enable additional recrystallization to occur. (In some experiments, the films were instead allowed to recrystallize for $30 \mathrm{~min}$. or for one week before mechanical analysis.)

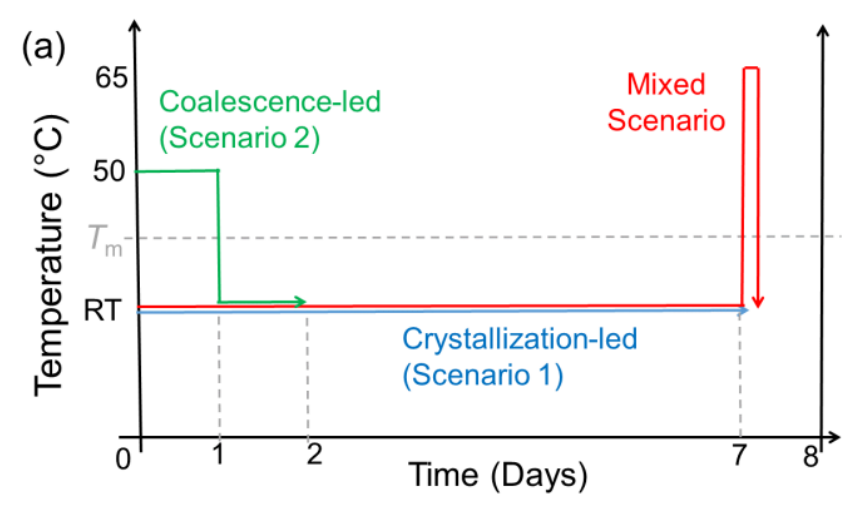




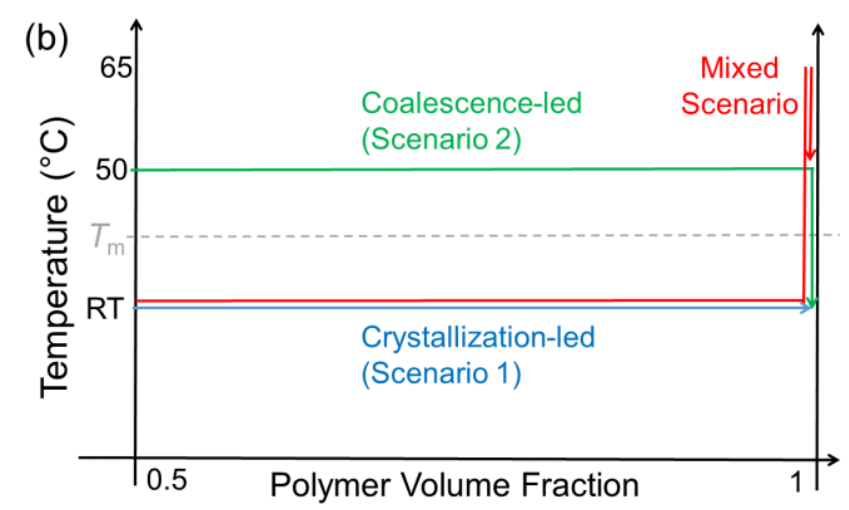

Figure 2. Processing of the poly(chloroporene) latex according to three different scenarios. (a) Temperature profiles over time. (b) Temperature profiles in relation to the film composition during drying. The melting temperature of poly(chloroprene) is shown as a gray dashed line. Diagrams are not drawn to scale.

Dynamic Mechanical Analysis (DMA). To study the effect of re-crystallization on the viscoelastic properties, dynamic mechanical analysis was performed on specimens held in tension. Temperature-sweep experiments were performed using a commercial instrument (Q800 from TA Instruments, New Castle, DE, USA). A frequency of $1 \mathrm{~Hz}$ with an amplitude of $0.1 \%$ strain was used across a temperature range from $-80{ }^{\circ} \mathrm{C}$ to $60{ }^{\circ} \mathrm{C}$ while heating at $5{ }^{\circ} \mathrm{C} / \mathrm{min}$. Samples were prepared by the same method as used for the tensile stress/strain analysis.

Microscopy. The surface morphology of unstrained poly(chloroprene) samples was investigated using cross-polarized optical microscopy. Experiments were performed on semi-crystalline polymer samples under crossed-polarizers using a Zeiss Axiophot microscope equipped with a Zeiss Axiocam camera.

Atomic force microscopy was performed on a commercial instrument (Ntegra, NT-MDT, Moscow) using gold-coated silicon cantilevers (NSG10, supplied by NT-MDT) with a nominal spring constant in the range from 5.5 to $22.5 \mathrm{~N} / \mathrm{m}$. Films were drop-cast onto glass coverslips and 
processed according to the various scenarios. Both height and phase contrast images were obtained using intermittent contact.

Films were deposited on glass coverslips and allowed to dry under ambient conditions. As-cast samples were imaged by AFM and optical microscopy at room temperature. The films were then heated to $65^{\circ} \mathrm{C}$ in an oven and held for $30 \mathrm{~min}$. Samples were re-imaged using AFM one week after cooling. Samples were also imaged using polarized optical microscopy immediately upon cooling, and after times of one day and one week.

Wide Angle X-Ray Scattering (WAXS). WAXS experiments were performed on unstrained, ascast samples of PC53 and PC94. Samples were prepared in the same way used for the stress/strain analysis. Additionally, samples of PC53 were tested $30 \mathrm{~min}$. and 1 day after heating. Samples were attached to a sample holder using double-sided tape and tested in a PANalytical X'Pert Pro diffractometer using a Cu- $\mathrm{K}_{\alpha}$ source, which has a characteristic wavelength $(\lambda)$ of $1.54 \AA$. The distance from the sample to the detector was $16.4 \mathrm{~cm}$. Samples were analyzed over a $2 \theta$ range between $10^{\circ}$ and $40^{\circ}$. Higher $2 \theta$ values were not studied because scattering from the sample holder interfered with the results. With a scan rate of $0.25 \% \mathrm{~min}$, the scan times were approximately two hours.

In other experiments, in situ WAXS measurements during sample stretching were made using a Xenocs Xeuss 2.0 instrument equipped with a micro-focus $\mathrm{Cu} \mathrm{Ka}$ source collimated with Scatterless slits. Wide angle scattering was measured on a Pilatus 100k detector mounted at an angle of $36^{\circ}$ to the beam direction, and at a distance of $164 \mathrm{~mm}$. Uniaxial stretching was carried out at room temperature on a tensile hot stage (Linkam, model TST250) at a rate of $1 \mathrm{~mm} / \mathrm{min}$.

The magnitude of the scattering vector $(q)$ is given by $q=4 \pi \sin \theta / \lambda$, where $2 \theta$ is the angle between the incident and scattered $\mathrm{X}$-rays, and $\lambda$ is the wavelength of the incident $\mathrm{X}$-rays. This gave 
a $q$ range for the detector of $1.3 \AA^{-1}$ to $3.3 \AA^{-1}$. An integration over all azimuth angles was performed on the 2D scattering pattern and the resulting $I(q)$ data were corrected for the absorption and background from the sample holder. From the reduced $I(q)$ curves, the crystallinity was calculated via peak deconvolution as the ratio between the area under Bragg peaks, $A_{\mathfrak{c}}$, and the total area under the WAXS curve, $A_{\mathrm{c}}+A_{a}$, with $A_{a}$ being the area under the amorphous halo:

$$
X_{c}=\frac{A_{c}}{A_{c}+A_{a}}
$$

The full width at the half-maximum (FWHM) of the (120) reflection was calculated by radial integration over a narrow $q$ range around the corresponding Bragg peak to obtain a Gaussian fitting of its azimuthal profile.

\section{Results}

\section{Crystallization in Poly(chloroprene) Films}

Wide angle x-ray scattering (WAXS) experiments showed that PC53 films are partially crystalline after film forming over one week and without any applied strain. Diffraction peaks in the $2 \theta$ range between $10^{\circ}$ and $40^{\circ}$ are identified in Figure 3. The peaks at $20^{\circ}, 22^{\circ} 26^{\circ}$ and 28.5 are in agreement with values found in the literature for the (120), (210), (220) and (211) planes, respectively, in orthorhombic crystals of poly(chloroprene) ${ }^{8}$ In contrast, no diffraction peaks are observed in the WAXS diffractogram for PC94. Only a weak amorphous halo is observed (Figure S4, Supporting Information). This result is explained by the presence of cross-links in the high-gel particles preventing crystallization, which is an effect that has been reported previously in the literature for poly(chloroprene) ${ }^{10}$ In the PC53 polymer, however, there is a sufficient density of non-cross-linked chains to allow crystallization to proceed. The relative amount of crystallinity in the samples is gauged by the peak areas (see Table 2). The data show that the as-cast PC53 film is 
partially crystalline. After heating to a temperature above $T_{\mathrm{m}}$ and cooling to room temperature, recrystallization occurs over time. The WAXS data obtained $30 \mathrm{~min}$. after this heating protocol show that the recrystallization is not complete; the fraction of crystallinity is lower than in the original as-cast film. (Note, that the WAXS scan was commenced $30 \mathrm{~min}$. after cooling to room temperature, but the scan itself took approximately two hours.) However, after aging the sample for one week, the crystallinity is comparable to what was found in the as-cast film.

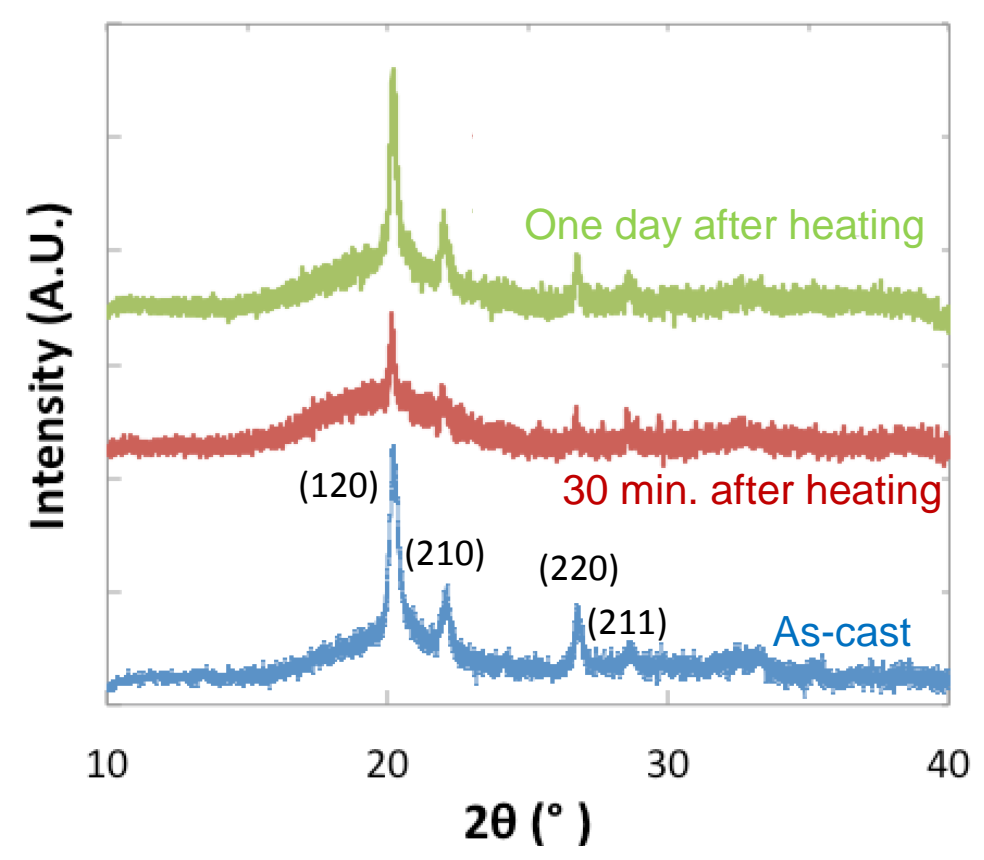

Figure 3. WAXS diffractograms of PC53 obtained at room temperature before and after heating at $65{ }^{\circ} \mathrm{C}$ for $30 \mathrm{~min}$. (annealing). Spectra are presented for the as-cast film (blue line), and commencing $30 \mathrm{~min}$. (red line) and one day (green line) after the heating step. The diffractograms are off-set by arbitrary amounts to allow for clearer viewing. The positions of crystal planes in the orthorhombic crystal structure are labelled. 
The WAXS analysis has indicated that there is some recrystallization over time in PC53 films. Optical microscopy was used to complement this analysis. Under crossed-polarizers, spherulites (on the order of a few $\mu \mathrm{m}$ ) are seen in the as-cast films (Figure 4a). An image taken immediately after heating at $65^{\circ} \mathrm{C}$ for $30 \mathrm{~min}$. (Figure $4 \mathrm{~b}$ ) shows no optical contrast in the film, indicating that all crystallinity has been removed by the melting step and recrystallization has not yet occurred. Over the course of one day, the crystallinity returned to the film (Figure 4c). The spherulites are smaller than those observed in the as-cast film. Their boundaries cannot be easily identified in the images. Additionally, a thin region around the edge of the sample appears to be completely amorphous, possibly because the thickness at the edge is below the size of the critical nucleus for crystallization. One week after heating (Figure 4d), the size of the spherulites remains smaller than those seen in the as-cast film. We attribute the reduction in spherulite size to an increase in nucleation sites in a film that is well interdiffused and not still undergoing the drying and coalescence process. Optical microscopy found no evidence for crystallization in the PC94 films, which is consistent with the findings of the WAXS and DSC.

AFM analysis of as-cast PC53 films revealed some surface texture, which could be attributed to the presence of crystals (Figure S5a). There is no indication of individual particle identity.

Table 2. Summary of the Peak Areas of the Characteristic WAXS peaks of Poly(chloroprene) Found in PC53 Films

\begin{tabular}{|c|c|c|c|c|}
\hline \multirow[b]{2}{*}{ Sample } & \multicolumn{4}{|c|}{ Peak Area (counts $\left.\times 2 \theta,^{\circ}\right)$} \\
\hline & (120) & (210) & (220) & (211) \\
\hline As Cast & 164.4 & 32.2 & 25.2 & 15.3 \\
\hline 30 min. after heating* & 35.8 & 17.2 & 10.2 & 10.1 \\
\hline
\end{tabular}




\begin{tabular}{|l|l|l|l|l|}
\hline 1 day after heating* & 99.1 & 37 & 24.2 & 8.3 \\
\hline
\end{tabular}

* Films were heated to $65^{\circ} \mathrm{C}$ for $30 \mathrm{~min}$.
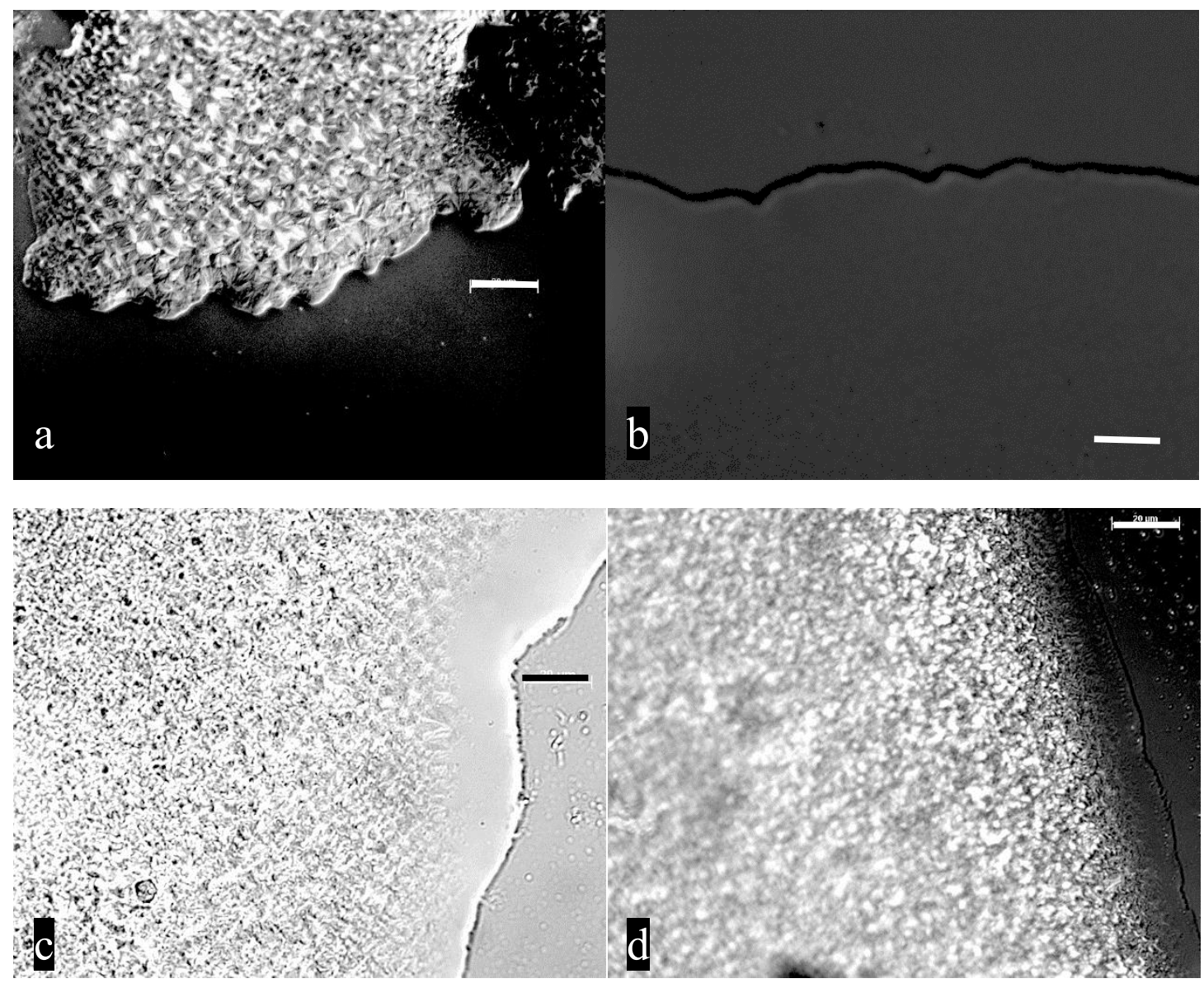

Figure 4. Optical microscopy images, taken under crossed-polarizers, of the edge region of PC53 films in different states: (a) as-cast; (b) immediately after heating to $65^{\circ} \mathrm{C}$ for $30 \mathrm{~min}$. and cooling to room temperature; (c) one day after this heating; (d) one week after this heating. Scale bar is 20 $\mu \mathrm{m}$ in each image.

\section{Effects of Coalescence and Crystallization on the Mechanical Properties}

Having characterized the crystallization of the poly(chloroprene) films, we next consider the effect of the competition between crystallization and coalescence on the mechanical properties. PC53 samples were film-formed under the three different scenarios, as described in the Materials 
and Methods section and shown in Figure 2. The stress/strain relationships of each were investigated under tension. A comparison is shown in Figure 5a.

Notably, there are large differences in the strains at failure for the three scenarios. The elastomer formed at room temperature (Scenario 1) fails at a strain of $c a .7 .5$ (equivalent to $750 \%$ ). When the film is formed at $50{ }^{\circ} \mathrm{C}$, which is above $T_{\mathrm{m}}$, and then left for one-day at room temperature (Scenario 2), the elastomer's strain at failure is significantly higher, at $c a$. 12. Furthermore, there is a pronounced strain hardening occurrence, marked by a sharp increase in the slope above a strain of $c a .3$, which can be attributed to the effects of SIC. ${ }^{17}$ The strength (stress at failure) is $c a .18$ $\mathrm{MPa}$, which is approximately three times greater than that observed for the crystallization-led elastomer in Scenario 1.

We conclude that when coalescence of the particles is allowed to proceed in the absence of crystals (Scenario 2), there is greater inter-particle cohesion. In contrast, when crystallization and coalescence take place in parallel (Scenario 1), we suggest that coalescence of some particles is blocked by the presence of crystal faces at inter-particle boundaries. Thus, in the presence of crystals, there are fewer polymer chains acting as ties between particles (see Figure 5b), creating weak points in the elastomer and reducing the tensile strength. Without crystallization, chains are free to diffuse across the particle boundaries where they entangle and dissolve the interface, resulting in a higher tensile strength. The effects of crystallinity on the yield point and strain hardening will be discussed later in this paper.

For many applications of elastomers, high extensibility coupled with high tensile strength is desired. We propose that in such a case, it is better to use the coalescence-led process. The result of the Scenario $1+2$ process, in which melting and recrystallization follows film formation, is shown for comparison in Figure 5. The strain at failure is remarkably high (ca. 22), and the tensile 
strength is only slightly lower than found for the Scenario 2 process. The microscopy presented in Figure 4 shows that in Scenario 1+2, the poly(chloroprene) recrystallizes after heating above $T_{\mathrm{m}}$ and cooling, but the average size of the spherulites is smaller than in the as-cast film. This difference in size is presumed to lead to the lower pseudo-yield point of $c a .2 \mathrm{MPa}$ observed for the Scenario 1+2 sample, coupled with an increased elongation at break. (A similar effect of decreasing spherulite size causing an increase in the strain at failure has been reported for isotactic polypropylene ${ }^{39}$ ) In this processing method, a film-formed elastomer with some pre-existing cohesive strength is melted, which has the effect of creating even greater cohesive strength than when film-forming at an elevated temperature.

(a)

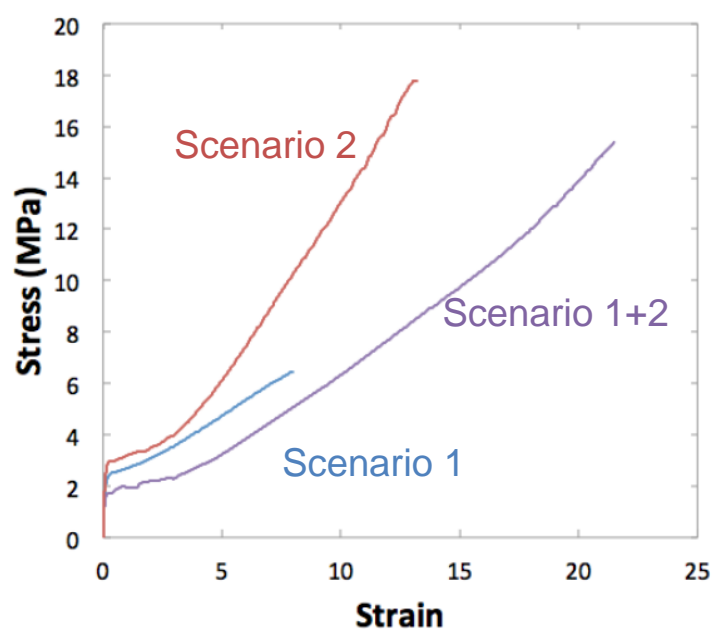

(b)

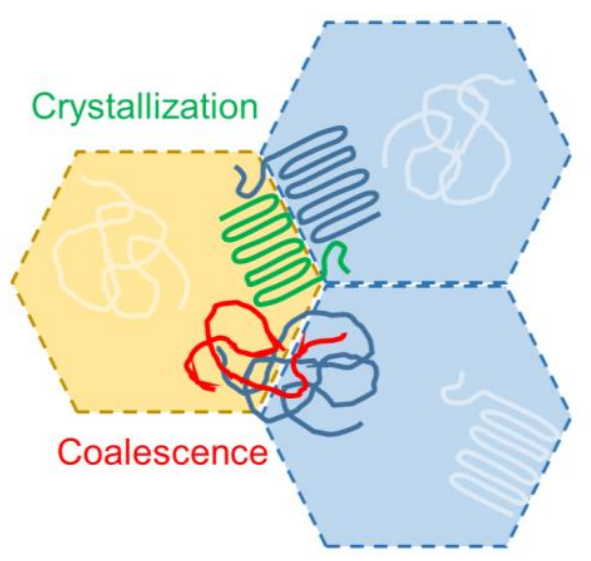

Figure 5. (a) Representative stress/strain curves of the PC53 elastomer formed under different film-forming conditions. Engineering stress and strain are presented for three scenarios: Crystallization-led elastomer, dried for one week at room temperature (blue line, Scenario 1); a coalescence-led elastomer, which was film-formed for 24 hours at $50{ }^{\circ} \mathrm{C}$ (above $T_{\mathrm{m}}$ ) then crystallized at room temperature for one day (red line, Scenario 2); a re-crystallized elastomer in which both crystallization and coalescence were encouraged in turn (purple line, Scenario 1+2). (b) Schematic diagram showing the cellular structure of a latex film. Polymer chains in crystals at 
particle interfaces (green line) have few ties to crystals in neighboring particles. With coalescence at particle/particle interfaces, random-coil chains (red line) extend across the boundary and provide inter-particle cohesion.

This initial result clearly demonstrates the sensitivity of the mechanical properties to the thermal processing. It also raises questions about the effect of the time dependence of the recrystallization on the development of strength and stiffness. The remainder of this paper will focus on the mixed scenario in blended poly(chloroprene) films, because of its potential to define and tune the mechanical properties.

\section{Mechanical Property Development in Recrystallized Poly(chloroprene) Elastomers}

DMA temperature sweep experiments have been used to probe the kinetics of re-crystallization and the effect on the evolving viscoelastic properties of the elastomers. The dynamic moduli of PC53 samples are presented in Figure 6. For the as-cast film (film formed via Scenario 1) the first drop in the storage modulus at around $-42{ }^{\circ} \mathrm{C}$ is attributed to the glass transition. The second drop starting at around $30{ }^{\circ} \mathrm{C}$ is attributed to the melting of crystals.

By comparing the as-cast sample to a sample immediately after heating to $65^{\circ} \mathrm{C}$ (above the $T_{\mathrm{m}}$ ) and cooling to $-80^{\circ} \mathrm{C}$, the effect of the loss of crystallinity on the storage modulus can be observed. There is a greater drop in the storage modulus above the glass transition temperature, because of the lack of crystals that would otherwise provide reinforcement. The effects of re-crystallization can be observed in the rise of the storage modulus between the temperatures of approximately 0 ${ }^{\circ} \mathrm{C}$ and $35{ }^{\circ} \mathrm{C}$ as crystals grow. As the heating rate is $5{ }^{\circ} \mathrm{C} / \mathrm{min}$. this temperature range corresponds to recrystallization over a period of seven minutes. However, during this time period, the modulus 
does not reach the value exhibited in the as-cast sample, which indicates that re-crystallization is incomplete. The modulus falls again above $35^{\circ} \mathrm{C}$ because the crystals melt.

When an elastomer is stored for one week at $22{ }^{\circ} \mathrm{C}$ after heating to $65^{\circ} \mathrm{C}$, more time is available for re-crystallization. In this case (purple line on Figure 6), the storage modulus follows a very similar trend to the as-cast sample. This result demonstrates the time-dependence of the recovery of the crystallinity. When only $30 \mathrm{~min}$. was allowed for re-crystallization at $22{ }^{\circ} \mathrm{C}$ (red line), there is an intermediate amount of increase in the storage modulus, indicating only partial recrystallization.

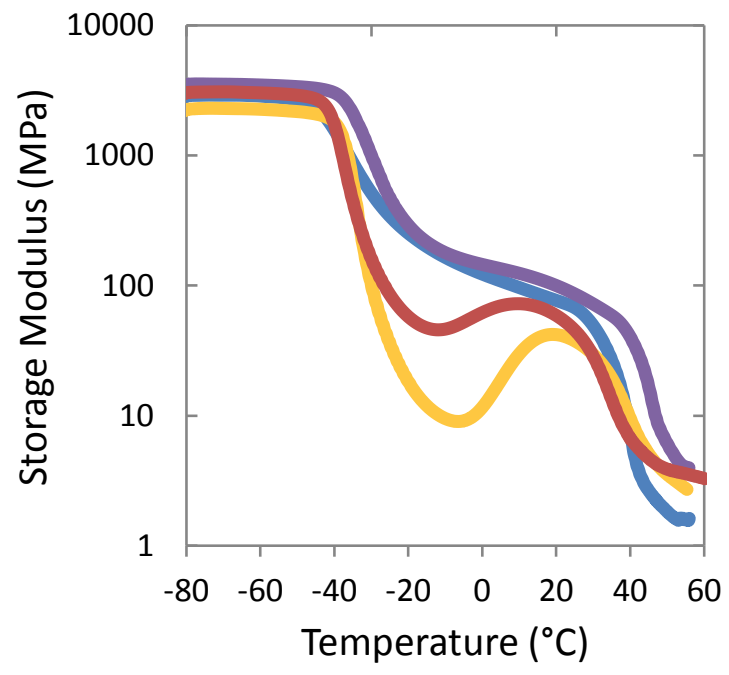

Figure 6. Results of DMA temperature sweeps on PC53 elastomers with different thermal processing: as-cast elastomer with crystallization-led processing (blue); immediately (0 min.) after heating to $65{ }^{\circ} \mathrm{C}$ and cooling at $5{ }^{\circ} \mathrm{C} / \mathrm{min}$. (yellow); after heating to $65{ }^{\circ} \mathrm{C}$ and recrystallizing for 30 min. at $22{ }^{\circ} \mathrm{C}$ (red); one week after heating to $65^{\circ} \mathrm{C}$ and recrystallizing for one week at $22{ }^{\circ} \mathrm{C}$ (purple). 
We next consider how the large-strain inelastic properties are affected by the recrystallization in the Scenario $1+2$ processing. Figure 7 a shows the stress/strain curves of PC53 at different times in the re-crystallization process in comparison to an as-cast film (crystallization-led). The data are shown up to the point of failure. It is apparent that melting and re-crystallization have dramatic effects on both the strength and the strain of failure of the PC53 elastomer.

When only $30 \mathrm{~min}$. is allowed for recrystallization at room temperature, the elastic modulus of the film is much lower in comparison to the as-cast sample, but there is greater extension before failure. The S-shape of the curve is typical for an elastomer. There is an initial linear elastic region, followed by a levelling in the slope because of chain disentanglements, and then a rise because of finite chain extensibility leading to strain hardening. ${ }^{29}$ According to the WAXS and DSC analysis (presented earlier), this result can be explained by the re-crystallization being incomplete after 30 min. The amorphous elastomer has a lower elastic modulus than when it is reinforced with crystals. The increase in the extension can be attributed to the effects of coalescence between particles during the melting step building film cohesion.

Allowing longer times (one day and one week) for a greater extent of recrystallization in the elastomers results in a strongly increased elastic modulus (at low strains) and a clearly-defined pseudo-yield point, in contrast to the results after $30 \mathrm{~min}$. . This increase in modulus is expected if the crystals act as hard fillers. The development of the pseudo-yield point is a signature of the transition from an amorphous to semi-crystalline elastomer. Additionally, the longer recrystallization time results in a higher tensile strength and the development of a strain-hardening response at higher strains.

With the aim of separating the effects of crystallization and coalescence, the results for PC53 are next compared to the results for PC94, which does not crystallize. With its higher gel content 
(greater cross-linking) but no crystallization, the PC94 elastomer presents strikingly different stress/strain data. (Figure 7b). There is a pronounced strain hardening in the PC94 film, which is attributed to the densely cross-linked network. Mooney-Rivlin analysis ${ }^{29,40}$ (Figure S6, Supporting Information) confirms the "classical" strain hardening of elastomer networks in as-cast PC94, whereas there is no hardening in the as-cast PC53. The pronounced strain-hardening (increased slope) in PC53 after one week of recrystallization must therefore require a network of crystals, ${ }^{17,41}$ which is otherwise absent after shorter recrystallization times, during SIC. Analysis of the polychloroprene SIC via in situ WAXS will be presented later in this paper.

In the PC94 films, the stress at failure is relatively low, and comparable to what was found for PC53 with only 30 min. of recrystallization. Also, no effect of the heating step $\left(65^{\circ} \mathrm{C}\right)$ on the PC94 films is obvious. The strains at failure do not differ strongly, which suggests that there is not a significant increase in the coalescence after the heating step. The strains at failure for all of the PC94 samples are lower than what are found for the recrystallized PC53 elastomers. This difference can be explained by the presence of dense cross-linking within the PC94 gel particles restricting coalescence and reducing film cohesion. Additionally, the tensile strength and strain hardening is weaker in the PC94 compared to the recrystallized PC53, which is explained by the lack of reinforcing crystals and by the prevention of SIC.

These experiments reveal that the mechanical properties of poly(chloroprene) can be adjusted by controlling both the cross-linking network and the crystallinity (adjusted through the thermal processing). We were thus inspired to examine the processing and property relationships in elastomers made from blending PC53 and PC94 particles together in varying proportions. 
(a)

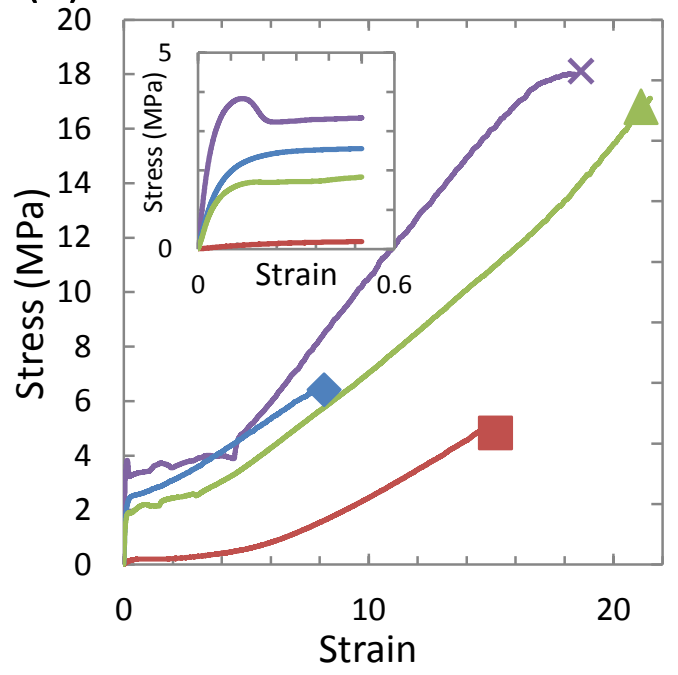

(b)

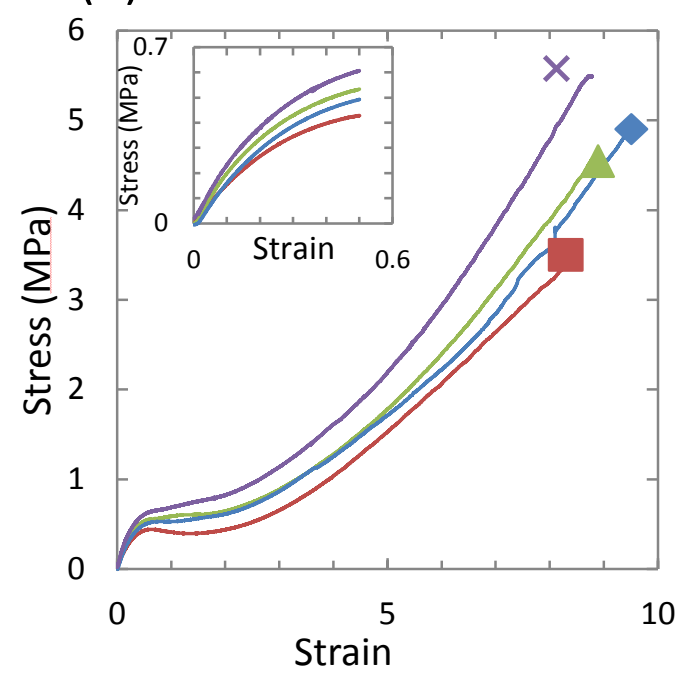

Figure 7. Representative large-strain data from (a) PC53 and (b) PC94 after various times and treatments: $(\diamond)$ as-cast, $(\square) 30 \mathrm{~min}$. after heating to $65^{\circ} \mathrm{C},(\triangle)$ one day after heating, and $(X)$ one week after heating. Data for the low-strain region are shown in the inset. Note the difference in scales between (a) and (b).

\section{Blends of Crystallizing and Non-Crystallizing Latex Particles}

Optical microscopy (Figure 8) readily shows that whereas as-cast PC94 films do not crystallize, a 1:1 blend (by volume of wet latex) of PC94 and PC53 does crystallize. The spherulite diameters are on the order $10 \mu \mathrm{m}$, which is far greater than the individual particle sizes (174 and $125 \mathrm{~nm}$, respectively). AFM analysis (Figure S5b) provides evidence that the two types of particles retain their identity (at least initially) in as-cast films. The crystals presumably grow mainly from the PC53 chains, but the spherulites eventually subsume the PC94 particles. 


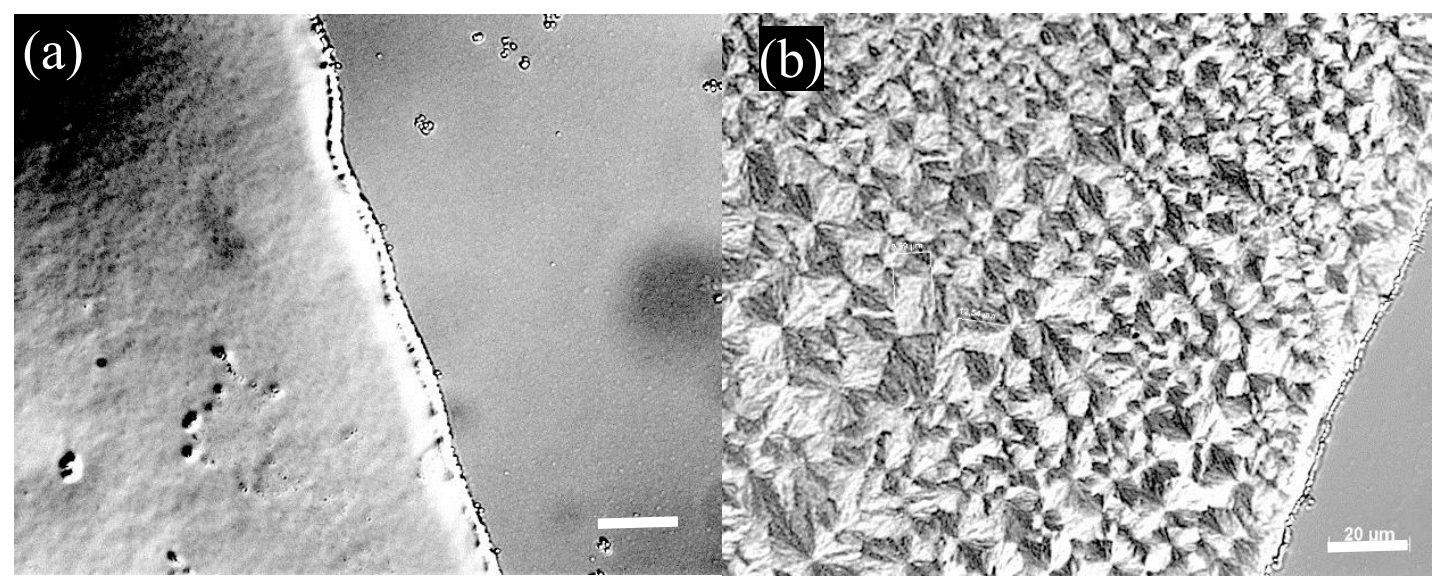

Figure 8. Optical microscopy images of the edge region as-cast films of (a) PC94 (a) and (b) a 1:1 PC53:PC94 blend taken under cross-polarizers. The darker gray region on the right side is the glass substrate. White scale bar is $20 \mu \mathrm{m}$ in both.

To investigate the extent to which PC94 influences the amount of crystallinity and also the kinetics of crystallization in particle blends, as-cast samples of PC53/PC94 latex blends were studied using differential scanning calorimetry (DSC). The crystalline fraction was estimated from the measured heat of melting (obtained from the area under the endothermic melting peaks) in relation to the reported latent heat of fusion for poly(chloroprene) of $95 \mathrm{~J} / \mathrm{g} .{ }^{42}$ This analysis found that the PC53 elastomers have an estimated crystallinity of 20 vol.\%. Elastomers were cast from blends of PC53 and PC94 in three different volume ratios (based on the wet latex): 1:3; 1:1 and 3:1. A linear relationship was found between the PC53 content and the crystalline content of the sample (Figure 9a). As such, we conclude that the presence of non-crystallizing PC94 particles neither hinders, nor promotes, crystallization in the PC53 phase. The PC94 particles coalesce but do not crystallize.

DSC was also used to study the re-crystallization kinetics of PC53 and its blends with PC94 by making measurements at varying hold times at $22{ }^{\circ} \mathrm{C}$ following crystal melting at $65{ }^{\circ} \mathrm{C}$ for 30 min. The results in Figure 9b indicate that the PC53 elastomer begins to re-crystallize within 3 
min. after cooling to a temperature of $22^{\circ} \mathrm{C}$. The extent of crystallinity increases over time until it reaches a maximum value of $17 \%$ after two hours. However, in the latex blends, there is a time delay before any crystallization is detected. The magnitude of this induction time increases with increasing PC94 content. After one day of recrystallization (outside of the calorimeter in this case), all samples have returned to the expected crystalline content of the PC53 phase prior to melting.

We propose that this induction time arises from the increased PC94 volume fraction reducing the size of the PC53 domains in which two or more particles are in close contact. As a result, the chance of a crystal forming with the critical nucleus size becomes less probable. Alig and Tadjbakhsch ${ }^{10}$ estimated that the critical nucleus size in poly(chloroprene) is $45 \mathrm{~nm}$, which is less than the size of an individual poly(chloroprene) latex particle. However, the critical nucleus size is usually underestimated in polymers, ${ }^{10}$ and so it could reasonably approach the $124 \mathrm{~nm}$ particle size. We propose that over time there could be some phase rearrangement that will allow crystals to nucleate, possibly at the boundary between PC53 particles, reminiscent of a template crystallization process. The number of nucleation sites is reduced and the nucleation time is longer when the number density of PC53 particle contacts is diluted by the addition of PC94 particles.
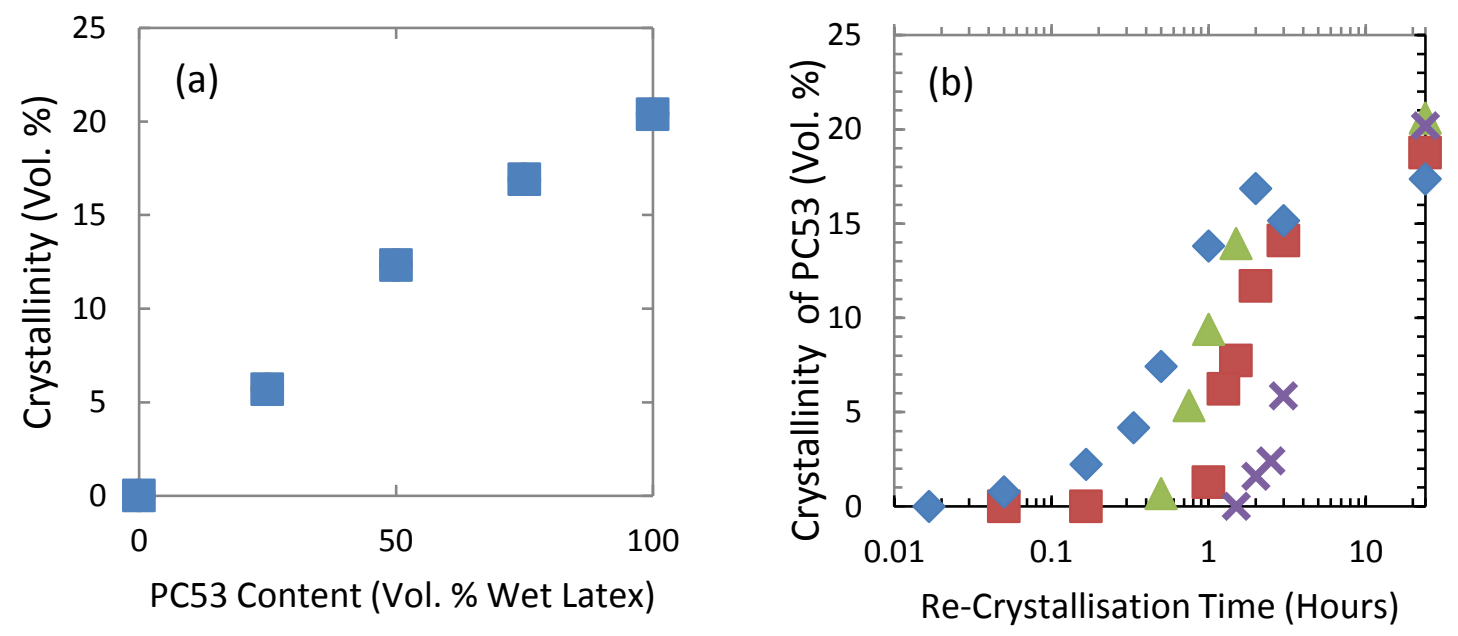
Figure 9. (a) Crystalline content as a function of PC53 content in blends with PC94 in the form of as-cast films, as was obtained from DSC analysis. (b) Time dependence of the re-crystallization of four elastomer compositions: $(\diamond)$ PC53; $(\triangle)$ 3:1 PC53:PC94 blend, ( $\square$ ) 1:1 blend, and (X) 1:3 PC53:PC94 blend. The crystallinity is expressed as the \% of the PC53 present. The fraction of PC53 in each blend was taken into account.

The inelastic large-strain properties were examined for the three blend compositions with three recrystallization times, following the same methods used for the PC53 and PC94 components. The data can be found in Figure S7 (Supporting Information). In Figure 10, we plot some key mechanical properties (Young's modulus, strain at failure, and fracture energy) of the blends as a function of the content of PC53. (The fracture energy was calculated from the area under the stress/strain curve.) We compare the results from as-cast elastomers to those that were recrystallized for times of 30 min., one day, and one week.

In the as-cast films, there is some synergy between the two components in the blends, which leads to a higher Young's modulus for both the 3:1 and the 1:1 blends in comparison to the individual constituents (PC53 and PC94, Figure 10a). That is, there is a positive interaction between the two types of poly(chloroprene) particle that leads to a Young's modulus higher than for each individual type. Similarly, the fracture energy is seen to be greater in all three as-cast blends in comparison to their constituents (Figure 10c).

Figure 10a shows the differences in the Young's modulus for samples with different PC53 content at three recrystallization times. For a time of 30 minutes after annealing, all blend compositions have very similar moduli because of the lack of crystallinity in the samples. After longer time periods of re-crystallization (i.e. one week), we see an increase in the moduli for the 
blends and the pure PC53 samples, with increasing PC53 content. On the other hand, no change is seen in the PC94 sample, which is as expected for an elastomer that does not crystallize over time.

Figure 10b shows the evolution of the strain at failure for the blends. Annealing increases the strain at failure for the $50 \%$ and $75 \%$ PC53 blends as well as the pure PC53. An increase of approximately $50 \%$ is seen after a 30 -min. recrystallization time for both samples, but smaller increases of $\sim 25 \%$ are seen for a time of one week. This suggests that in all three blends, the polymer crystals might be inhibiting coalescence in the as-cast films (Scenario 1). However, upon heating and melting the crystals, the particles have coalesced prior to their crystallization (Scenario 2), resulting in stronger interfaces.

The 1:3 blend and PC94 samples show no change in their strain at failure after being heated. This result is expected for PC94 as there is no crystallinity to inhibit coalescence. For the 1:3 blend, the observed induction time for the onset of crystallinity is long enough (of the order of two hours) that coalescence-led film formation becomes possible. That is, in this as-cast film, coalescence is essentially complete prior to crystallization.

Figure 10c shows the differences in the fracture energy for each composition. As was found in the Young's modulus data, no change is seen in PC94 over time after heating the as-cast film. In the blend samples, however, the fracture energy increases with increasing PC53 content. In the PC53 elastomer, the energy is significantly greater after one week of recrystallization.

Figure 10d explores the relationship between the Young's modulus and the total amount of crystallinity in blends of the two types of poly(chloroprene). We observe an apparent gradual increase in the Young's modulus with an increase in the heat of crystal melting (proportional to the total amount of crystallinity), as is shown in Figure 7a. This result is explained by the reinforcement of the elastomer with crystals. However, the Young's modulus for a PC53 film after 
one week of re-crystallization is much greater than the values expected by a simple monotonic relationship. This result demonstrates that the modulus is determined not only by the volume fraction of crystals but also by their size and spatial distribution.
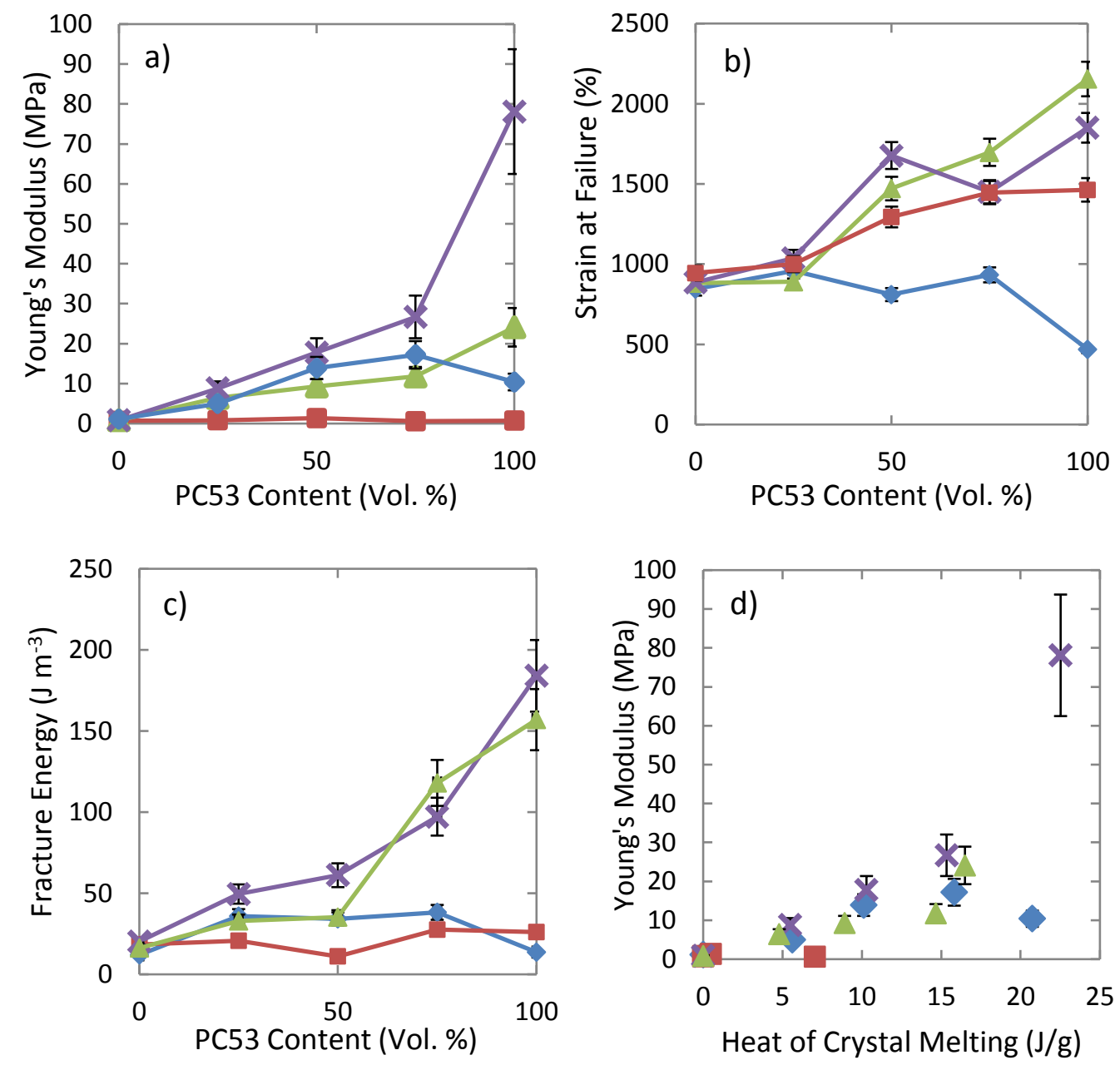

Figure 10. Mechanical properties of elastomer films obtained from blending PC53 and PC94. (a) Young's Modulus; (b) strain at failure; and (c) fracture energy. (d) Young's modulus plotted against the heat of crystal melting of the samples found in DSC experiments. Data are shown for the four types of processing: $(\diamond)$ As-cast; ( $\square) 30$ min. after heating; $(\Delta)$ one day after heating; and $(\times)$ one week after heating. The solids lines are guides to the eye. 


\section{Strain-Induced Crystallization in Poly(chloroprene)}

Next we investigate the structural evolution upon uniaxial stretching of PC53 and its 1:1 blend with PC94 to study the phenomenon of strain-induced crystallization in these materials. Figure 11 shows two-dimensional WAXS patterns obtained at different times during tensile strain at room temperature. Initially, PC53 (Figure 11a) presents several arc reflections, with (120) and (210) being the most intense, which do not show any sign of preferential orientation. As stretching proceeds, the intensity of these reflections increases and their arcs become narrower, indicating an increase in the degree of crystallinity and chain orientation. In the case of the 1:1 blend of PC53 and PC94 (Figure 11b), a similar behavior is observed, although the initial crystallinity appears to be significantly smaller and has less defined reflections.

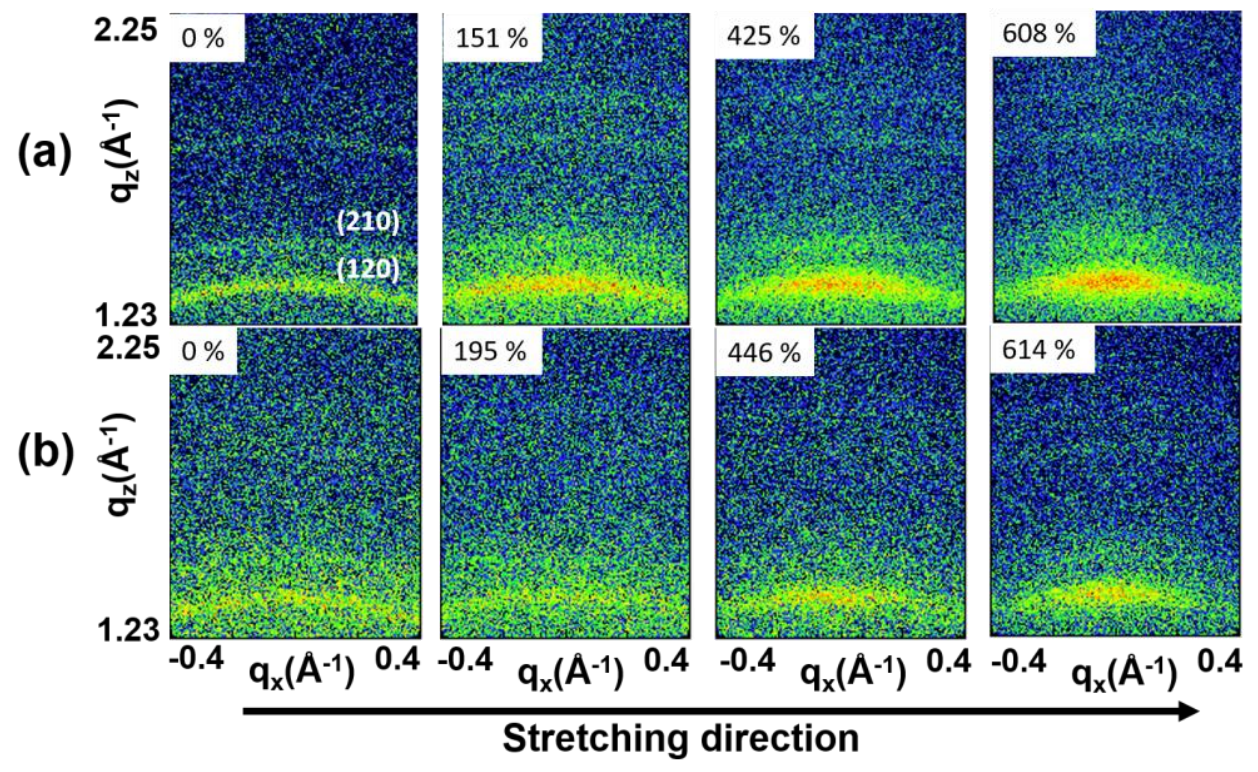

Figure 11. Two-dimensional WAXS patterns of (a) PC53 and (b) 1:1 blend of PC53 and PC94 during in situ stretching at room temperature. The strain corresponding to each frame is noted at its upper left corner.

These observations have been qualitatively confirmed by calculating the degree of crystallinity, $X_{\mathrm{c}}$ (Figure 12a). PC53 presents an initial degree crystallinity of 0.23 which steadily increases with 
increasing strain up to 0.46 at about $500 \%$ strain, where it seems to be approaching an asymptotic value. (This initial value of crystallinity is comparable to the value of 0.2 found via DSC.) The PC94:PC53 blend starts from a lower crystallinity of 0.12 , which increases to a maximum of 0.27 at a strain of $c a .500 \%$. The crystallinity in this $50 \%$ blend is approximately one-half of the crystallinity of the PC53 (see the dashed line in Figure 12a). This result can be explained by the crystallinity occurring only in the PC53 component, and it is consistent with the DSC analysis in Figure 9a. The presence of the PC94 does not have a strong influence on the crystallinity in this respect. However, in a study of natural rubber, Tosaka et al. concluded that fully stretched chains in cross-linked networks act as nucleation sites for the growth of lamellar crystals. ${ }^{7}$ With increased cross-linking density, there is a greater number density of co-aligned chains that can nucleate crystallization. In our system, the heavily cross-linked poly(chloroprene) chains in the PC94 particles might not be in close enough proximity to the non-cross-linked chains, or perhaps the network chains are not bearing enough of the load to be extended fully. Both the PC53 and the blend show in Figure 12b clearly decreasing values of the FWHM of the (120) reflection with increasing strain, which indicates there is increasing chain orientation.

To obtain an estimate of the crystallite size in these two samples, a Scherrer analysis was performed on the WAXS data. Using two different methods to determine the diffraction peak widths in reciprocal space, ${ }^{43,44}$ the mean thickness of the crystalline layer in the unstrained spherulites' lamella was estimated to be on the order of $20 \mathrm{~nm}$ for both the PC53 as-cast film and the PC53:PC94 1:1 blend film. The presence of the non-crystallizing particles did not affect the crystalline layer thickness. (These calculations are presented in the Supporting Information.) The crystalline layer thickness did not change significantly with increasing strain. See Figure S8. The 
value of the layer thickness is slightly larger than what has been reported elsewhere for the lamellar periodicity in vulcanized poly(chloroprene) crystallized under strain while at room temperature. ${ }^{45}$
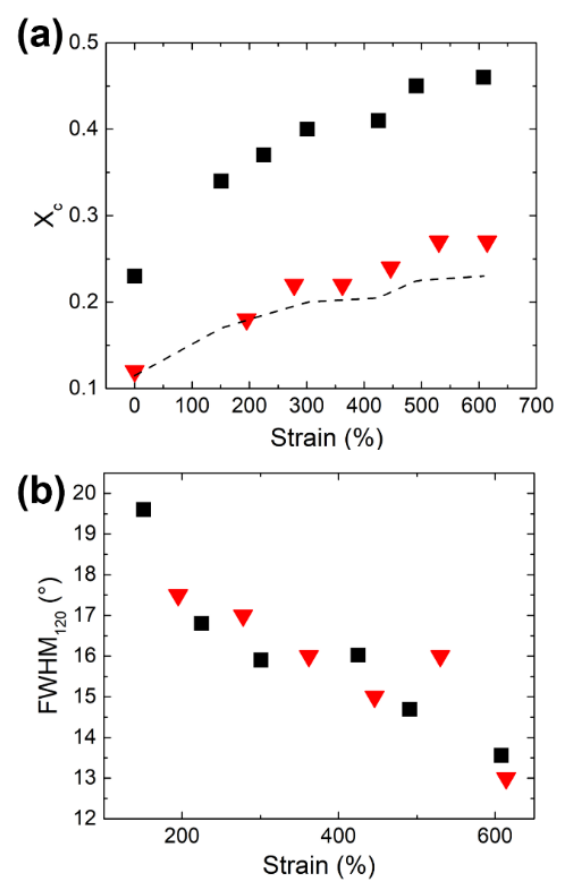

Figure 12. WAXS structural parameters of PC53 and its 1:1 blend with PC94 as a function of strain: (a) Crystallinity calculated from 1D profiles obtained via azimuthal integration of the patterns in Figure 11, and (b) Full width at the half-maximum (FWHM) values for the (120) reflection obtained from a graph of scattered intensity versus azimuth angle. The dashed line in (a) represents $50 \%$ of the crystallinity presented in PC53, as a comparison for the 1:1 blend.

These results show that the decrease in crystallinity caused by the introduction of a fraction of heavily cross-linked, non-crystallizing poly(chloroprene) particles can be reversed by taking advantage of the SIC phenomenon. Moreover, the degree of chain orientation after stretching is higher than that in the non-cross-linked poly(chloroprene) prior to orientation. Thus, the loss in some mechanical properties (e.g. Young's modulus) in the poly(chloroprene) elastomers with better coalescence can be overcome through strain-induced crystallization when in use. 


\section{Conclusions}

We have shown the importance of the competition between crystallization and coalescence in determining the mechanical properties of films cast from semi-crystallizable poly(chloroprene) latex particles. In the as-cast crystallizing elastomers, there is evidence for a lack of cohesion between particles presented in the film's low strain at failure. In this scenario, the crystallization rate is fast relative to the rate of coalescence. When there are crystals at the particle interfaces, there could be fewer connecting chains between the crystal domains. Conversely, when coalescence is induced at a temperature above the crystal melting point, and so precedes the crystallization, there is a higher strain at failure and a significantly higher tensile strength.

We showed that blending crystallizable poly(chloroprene) particles and heavily cross-linked, non-crystallizing particles provides an opportunity to tune the mechanical properties in combination with the recrystallization process. After heating to melt the crystals and then cooling to recrystallize them, an increase in the strain at failure was observed for elastomers containing at least 50 vol.\% of crystallizable poly(chloroprene). We attribute this finding to further particle coalescence occurring when the crystals are melted. There is also an increase in the elastic modulus and the pseudo-yield point over time during re-crystallization. Smaller crystals are observed after recrystallization than are seen in the as-cast elastomer, which we attribute to an increase in nucleation sites. This recrystallized structure in the crystallizable polychloroprene (PC53) contributes to its particularly high elastic modulus.

In films derived from particle blends, an induction time in the onset of crystallization was discovered. As the fraction of the crystallizable poly(chloroprene) fraction is decreased, an 
increase in the induction time is observed. This result can be explained by smaller, more dispersed regions of crystallizable poly(chloroprene) resulting in a longer average nucleation time.

Strain-induced crystallization was demonstrated using WAXS analysis for the crystallizing latex film and blend films containing the non-crystallizing, heavily cross-linked latex particles. There is no evidence that the presence of the non-crystallizing particles influences the strain-induced crystallization of the crystallizable particles. Recrystallized films (prepared via Scenario 1+2) show a pronounced strain hardening (signaled by an increase in the slope in Figure 7a) which is not seen in the as-cast film. However, the as-cast film exhibits SIC (Figure 12), so SIC does not necessarily lead to a strong strain-hardening behavior. The strain-hardening is more pronounced in films that are fully coalesced and that have higher fractions of crystallinity (following longer times of recrystallization).

In summary, these experiments have illustrated how the control of the relative rates of particle coalescence and (re)crystallization is important in tuning the mechanical properties of polychloroprene latex films. Furthermore, blending crystallizable and non-crystallizable particles, coupled with strain-induced crystallization, offers a powerful means to control the elastomeric properties.

\section{ASSOCIATED CONTENT}

Supporting Information. The following additional data are available: ${ }^{1} \mathrm{H}$ NMR spectra to determine the isomer content; example DSC thermograms in a heat-cool-heat cycle; a scheme of the DSC protocol; X-ray scattering data for the non-crystallizing poly(chloroprene) PV94; atomic force microscopy images of as-cast and re-crystallized films of PC93 and PC53:PC94 
blends; Mooney-Rivlin plots for PC53 and PC94; representative stress-strain curves for PC53:PC94 blends during recrystallization.

\section{AUTHOR INFORMATION}

Corresponding Author

*e-mail: j.keddie@surrey.ac.uk

Present Addresses

$\dagger$ P2i, 9-12 North Central, 127 Olympic Avenue, Milton Park, Oxfordshire, OX14 4SA, UK \# Queen's University Belfast, University Rd, Belfast BT7 1NN, UK

\$ Mundipharma, 205 Cambridge Science Park Rd., Milton, Cambridge CB4 0GZ

\section{Author Contributions}

The manuscript was written through contributions of all authors. All authors have given approval to the final version of the manuscript.

\section{Funding Sources}

Funding for the $\mathrm{PhD}$ research of PR was generously provided by Synthomer (UK) Ltd.

\section{ACKNOWLEDGMENT}

We thank Dr. Tara Schiller (University of Warwick) for helpful advice on the WAXS experiments, and Dr. Steven Huband at the University of Warwick X-ray Facility for technical 
assistance in the WAXS measurements and analysis. We also thank Yuxiu Chen for the zeta potential measurements, Violeta Doukova for general laboratory assistance, Qinmin Zhang for NMR technical support, and Daniel Driscoll for WAXS support at the University of Surrey.

\section{REFERENCES}

(1) Anderson C.D.; E.S. Daniels, E.S. Emulsion Polymerisation and Latex Applications, (Humphreys, S. Editor; Rapra Review Reports Vol. 14) Rapra Technology Limited: Shrewsbury, U.K., 2003.

(2) Hamilton, R.G. Diagnosis of natural rubber latex allergy. Methods, 2002, 27, 22.

(3) Shah, D., Chowdhury, MM. Rubber Allergy. Clinics in Dermatology, 2011, 29, 278.

(4) Morton, M. Rubber Technology, Springer: Dordecht, The Netherlands, 1987.

(5) Wood, L.A.; Bekkedahl, N. Crystallization of Unvulcanized Rubber at Different Temperatures. J. Appl. Phys. 1946, 17, 362.

(6) Candau, N.; Chazeau, L.; Chenal, J.M.; Gauthier, C.; Munch, E. A comparison of the abilities of natural rubber (NR) and synthetic polyisoprene cis-1,4 rubber (IR) to crystallize under strain at high strain rates. Phys. Chem. Chem. Phys. 2016, 18, 3472.

(7) Tosaka, M.; Murakami, S.; Poompradub, S.; Kohija, S. Orientation and Crystallization of Natural Rubber Network As Revealed by WAXD Using Synchotron Radiation. Macromolecules, 2004, 37, 3299.

(8) Birkett Clews, C.J., Roper Robinson, H. The Structure of Polychloroprene. Proc. R. Soc. A, $1942,180,100$. 
(9) Zhang, P.; Huang, G.; Qu, L.; Nie, Y.; Weng, G.; Wu, J. Strain-induced Crystallization Behavior of Polychloroprene Rubber. J. Appl. Polym. Sci. 2011, 121, 37.

(10) Alig, I.; Tadjbakhsch, S. Film Foration and Crystallization Kinetics of Polychloroprene Studied by an Ultrasonic Wave Reflection Method. J. Polym. Sci., Part B: Polym. Phys. 1998, 36, 2949.

(11) Katz, J.R. X-ray spectrographic studies on stretched rubber and their possible significance for the problem of the elongation properties of this substance. Naturwissenschaften, 1925, 13, 410.

(12) Bruning, K.; Schneider, K.; Roth, S.V.; Heinrich, G. Kinetics of Strain-Induced Crystallization in Natural Rubber Studied by WAXD: Dynamic and Impact Tensile Experiments. Macromolecules 2012, 45, 7914.

(13) Candau, N.; Laghmach, R.; Chazeau, L.; Chenal, J.M.; C. Gauthier, C.; Biben, T.; Munch, E. Strain-Induced Crystallization of Natural Rubber and Cross-Link Densities Heterogeneities. Macromolecules 2014, 47, 5815.

(14) Qu, L.; Huang, G.; Nie, Y.; Wu, J.; Weng, G.; Zhang, P. Strain-induced crystallization behavior of natural rubber and trans-1,4-polyisoprene crosslinked blends. J. Appl. Polym. Sci. 2011, 120, 1346.

(15) Toki, S.; Che, J.; Rong, L.; Hsiao, B.S.; Amnuaypornsri, S.; Nimpaiboon, A.; Sakdapipanich, J. Entanglements and Networks to Strain-Induced Crystallization and StressStrain Relations in Natural Rubber and Synthetic Polyisoprene at Various Temperatures. Macromolecules 2013, 46, 5238. 
(16) Conradt, R.N.J.; Heise, B.; Kilian, H.G. Crystallization in stretched and unstretched rubber - thermodynamics and kinetics. Prog. Colloid Polym. Sci. 1992, 87, 85.

(17) Le Gac, P.-Y.; Albouy, P.-A.; Petermann, D. Strain-induced crystallization in an unfilled polychloroprene rubber: Kinetics and mechanical cycling. Polymer 2018, 142, 209.

(18) Keddie, J.L.; Routh, A.F. Fundamentals of Latex Film Formation: Processes and Properties; Springer: Dordecht, 2010.

(19) Grove, R.; Routh, A.F. Film Deposition and Consolidation During Thin Glove Coagulant Dipping. J. Polym. Sci. Part B: Polym. Phys. 2017, 55, 1633.

(20) Gonzalez, E.; Tollan, C.; Chuvilin, A.; Barandiaran, M.J.; Paulis, M. Determination of the Coalescence Temperature of Latexes by Environmental Scanning Electron Microscopy. ACS Appl. Mater. Interfaces 2012, 4, 4276.

(21) Routh, A.F.; Russel, W.B.; Tang, J.; El-Aasser, M.S. Process Model for Latex Film Formation: Optical Clarity Fronts. J. Coat. Technol. 2001, 73(916), 41.

(22) Odrobina, E.; M.A. Influence of Entanglements on the Time Dependence of Mixing in Nonradiative Energy Transfer Studies of Polymer Diffusion in Latex Films. Macromolecules 2001, 34, 6029.

(23) Kim, K.D.; Sperling, L.H.; Klein, A.; Hammouda, B. Reptation Time, Temperature, and Cosurfactant Effects on the Molecular Interdiffusion Rate during Polystyrene Latex Film Formation. Macromolecules 1994, 27, 6841. 
(24) Wu, J. Pablo Tomba, J.P., Winnik, M.A., Farwaha, R.; Rademacher, J. Temperature Dependence of Polymer Diffusion in Poly(vinyl acetate-co-dibutyl maleate) Latex Films. Macromolecules, 2004, 37, 2299.

(25) Yoo, S.; Harelle, L.; Daniels, E.S.; El-Aasser, M.S.; Klein, A. Interfacial Aspects of Strength Development in Poly(methyl methacrylate)-based Latex Systems. J. Appl. Polym. Sci. 1995, 58,367 .

(26) Aradian, A., Raphaël, E., de Gennes, P.G. Strengthening of a Polymer Interface: Interdiffusion and Cross-Linking. Macromolecules, 2000, 33, 9444.

(27) Aradian, A., Raphaël, E., de Gennes, P.G. A Scaling Theory of Competition between Interdiffusion and Cross-Linking at Polymer Interfaces. Macromolecules, 2002, 35, 4036.

(28) Fischer E.; Henderson, J.F. J. Polym Sci., Pt. B: Polym. Phys. 1967, 5, 377.

(29) Rubinstein, M.; Colby, R.H. Polymer Physics, Oxford University Press: Oxford, 2003.

(30) Abdel-Goad, M.; Pyckhout-Hintzen, W.; Kahle, S.; Allgaier, J.; Richter, D.; Fetters, L.J. Rheological Properties of 1,4-Polyisoprene over a Large Molecular Weight Range. Macromolecules 2004, 37, 8135.

(31) He, Y.; Daniels, E.S.; Klein, A.; El-Aasser, M.S. Elastomeric Films from Structured Latexes. J. Appl. Polym. Sci. 1997, 64, 1143.

(32) Agarwal, N.; Farris, R.J. Mechanical properties of acrylic based latex blend coatings. Polym. Eng. Sci. 2000, 40, 376. 
(33) Vidovska, D.; Maurer, F. H. J. Tensile properties and interfacial interactions of bimodal hard/soft latex blends. Compos. Interfaces, 2006, 13, 819.

(34) Utara, S.; Boochathum, P. Novel dynamic vulcanization of polyethylene and ozonolysed natural rubber blends: Effect of curing system and blending ratio. J. Appl. Polym. Sci. 2011, 120, 2606.

(35) Zhang, P.; G. Huang, G.; Qu, L.; Nie, Y.; Weng, G. Study on the Self-Crosslinking Behavior Based on Polychloroprene Rubber and Epoxidized Natural Rubber. J. Appl. Polym. Sci. 2012, 125, 1084.

(36) Rattanasom, N.; Kueseng, P.; Deeprasertkul, C. Improvement of the mechanical and thermal properties of silica-filled polychloroprene vulcanizates prepared from latex system. $J$. Appl. Polym. Sci. 2012, 124, 2657.

(37) Zhang, K.; Shen, H.; Zhang, X.; Lan, R.; Chen, H. Preparation and Properties of a Waterborne Contact Adhesive Based on Polychloroprene Latex and Styrene-Acrylate Emulsion Blend. J. Adhes. Sci. Technol. 2009, 23, 163.

(38) Makhiyanov, M., Determination of the Microstructure of Polychloroprenes from $1 \mathrm{H}$ and 13C NMR Data. Russ. J. Appl. Chem. 2011, 84, 454.

(39) Ehrenstein, G.W.; Theriault, R.P. Polymeric Materials: Structure, Properties, Applications. Hanser Verlag: Berlin, 2001

(40) Rubinstein, M.; Panyukov, S. Elasticity of Polymer Networks. Macromolecules 2002, 35, 6670. 
(41) Albouy, P.A.; Vieyres, A.; Pérez-Aparicio, R.; Sanséau, O.; Sotta, P. The impact of straininduced crystallization on strain during mechanical cycling of crosslinked natural rubber. Polymer 2014, 55, 4022 .

(42) Wingard, D. Use of DSC and DMA to Study Rubber Crystallization as a Possible Cause for a Tear in a Neoprene Glove Used in a Space Shuttle Pressurized Astronaut Suit. J. Therm. Anal. Calorim. 2010, 102, 469.

(43) Zhang, W.; Yan, Q.; Ye, K.; Zhang, Q.; Chen, W.; Meng, L.; Chen, X.; Wang, D.; Li, L. The effect of water absorption on stretch-induced crystallization of poly(ethylene terephthalate): An in-situ synchrotron radiation wide angle X-ray scattering study. Polymer, 2019, 162, 91.

(44) Hejase, H.; Hayek, S.S.; Qadri, S.; Haik, Y. MnZnFe nanoparticles for self-controlled magnetic hyperthermia. J. Magn. Magn. Mater., 2012, 324, 3620.

(45) Krigbaum, W.R.; Balta, Y.I.; Via, G.H. A reversible change in long period spacing with temperature. Polymer, 1966, 7, 61.

\section{TOC Image}

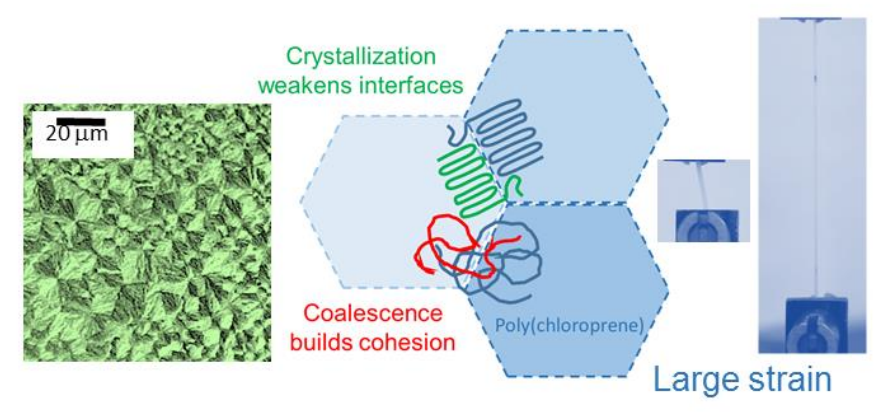

